\title{
Fumaric acid esters in the management of psoriasis
}

\author{
This article was published in the following Dove Press journal: \\ Psoriasis: Targets and Therapy \\ 5 January 2015 \\ Number of times this article has been viewed
}

\section{Deepak MW Balak}

Department of Dermatology, Erasmus Medical Center, Rotterdam, the Netherlands
Correspondence: Deepak MW Balak Department of Dermatology, Erasmus Medical Center, Burg. s'jacobplein 5I, 3015 CA Rotterdam, the Netherlands $\mathrm{Tel}+3 \mid 10703$ | I87

Fax +3। 107033822

Email d.balak@erasmusmc.nl or balak.dmw@gmail.com
Abstract: Fumaric acid esters (FAE) are small molecules with immunomodulating, anti-inflammatory, and anti-oxidative effects. FAE were introduced as a systemic psoriasis treatment in 1959 and empirically developed further between 1970 and 1990 in Germany, Switzerland, and the Netherlands. The development of FAE as psoriasis treatment did not follow the traditional drug development phases. Nonetheless, in 1994 FAE were approved in Germany for the treatment of severe plaque psoriasis. FAE are currently one of the most commonly used treatments in Germany, and FAE are increasingly being used as an unlicensed treatment in several other European countries. To date, six randomized controlled trials and 29 observational studies have evaluated FAE in a combined total of 3,439 patients. The efficacy and safety profile of FAE is favorable. About $50 \%-70 \%$ of patients achieve at least $75 \%$ improvement in psoriasis severity after 16 weeks of treatment. Common adverse events of FAE include gastrointestinal complaints and flushing symptoms, which lead to treatment discontinuation in up to $40 \%$ of patients. Lymphocytopenia, eosinophilia, and proteinuria are commonly observed during FAE treatment, but rarely require treatment discontinuation. The long-term safety profile of continuous FAE treatment is favorable without an increased risk for infections, malignancies, or other serious adverse events. There are no known drug-interactions for FAE. The 2009 European evidence-based S3-guidelines on psoriasis treatment recommend FAE and suggest it as a firstline systemic treatment for moderate-to-severe plaque psoriasis. This review is aimed to give an overview of FAE treatment in the management of psoriasis.

Keywords: fumaric acid esters, fumarates, dimethyl fumarate, Fumaderm, psoriasis, systemic treatment

\section{Introduction}

Fumaric acid esters (FAE), also known as fumarates, are ester derivatives of fumaric acid. ${ }^{1}$ Fumaric acid is an intermediate in the citric acid cycle, which is a basic cellular process that generates energy in the mitochondria. ${ }^{2}$ In 1959, the German chemist Walter Schweckendiek, who suffered from psoriasis himself, postulated that psoriasis occurred due a deficiency in fumaric acid levels leading to defects in the citric acid cycle, and that oral supplementation of fumaric acid might neutralize these defects. ${ }^{3}$ Given that oral fumaric acid caused too much gastrointestinal irritation, Schweckendiek instead used the esters of fumaric acid in several self-experiments. Although Schweckendiek's original hypothesis regarding an aberrant citric acid cycle underlying psoriasis were never proven, patients with psoriasis seemed to benefit from oral treatment with a mixture of different FAE with dimethyl fumarate (DMF) and monoethyl fumarate (MEF)-salts. ${ }^{4}$ In the 1970s, the German general practitioner 
Gunther Schäfer standardized FAE treatment with oral and topical application of FAE in combination with a diet. Using this treatment regimen, Schäfer reported good effectiveness results in treating psoriasis patients with FAE on a large scale in a specialized clinic in Leysin, Switzerland. ${ }^{5,6}$ Initial clinical studies by German dermatologists, however, could not confirm the beneficial effects of FAE in psoriasis treatment. ${ }^{7,8}$ Moreover, there were growing concerns on the safety of FAE as several cases were reported of acute renal toxicity in patients treated with FAE. ${ }^{9}$ This led to a stop in the development of FAE as psoriasis treatment for over a decade. Following the mid-1980s, however, there was a revival of interest in FAE treatment among academic dermatologists, partly under the influence of psoriasis patient associations. ${ }^{6,10}$ The first clinical observational studies were conducted by dermatology centers in Switzerland and in the Netherlands, which were published in 1987 and 1989 , respectively. ${ }^{10,11}$ Around the same time, the Dutch physician Leonard Kunst developed and treated psoriasis patients with a novel FAE formulation containing only DMF, omitting the MEF-salts. ${ }^{12}$ In the early 1990s, the first randomized, placebo-controlled trials that evaluated FAE in psoriasis were published, in which efficacious responses and a good safety profile were observed in patients with chronic plaque psoriasis. ${ }^{13,14}$ Following these clinical trials, FAE treatment became approved in 1994 in Germany for the systemic treatment of severe psoriasis in adult patients. The licensed FAE-formulation contained a mixture of DMF and MEFsalts, which was marketed as Fumaderm (Fumapharm AG, Switzerland). Fourteen years later, in 2008, the German registration for FAE treatment with Fumaderm was expanded to include moderate psoriasis in adults. ${ }^{15}$

Currently, FAE are one on the most commonly used systemic treatments in Germany. ${ }^{16} \mathrm{FAE}$ are licensed only in Germany for the treatment of moderate-to-severe psoriasis. To date, there is no European Medicines Agency or US Food and Drug Administration (FDA) approved use of FAE in psoriasis patients. ${ }^{17}$ Despite this, FAE are increasingly being used as an unlicensed treatment in several European countries, including the UK, ${ }^{18}$ Ireland, ${ }^{19}$ the Netherlands, ${ }^{20}$ Austria, ${ }^{21}$ and Italy. ${ }^{22,23}$ Moreover, the 2009 European S3-guidelines on the systemic treatment of psoriasis vulgaris suggest FAE as a systemic treatment for psoriasis with a favorable riskbenefit ratio. ${ }^{24}$ In other parts of the world, FAE are so far not available for the treatment of psoriasis.

The mechanisms of action by which FAE improve psoriasis are not yet completely understood. ${ }^{25}$ FAE are thought to elicit their effects through multiple immunomodulating effects. ${ }^{1}$ Recent experimental studies have described various immunomodulatory, anti-inflammatory, and anti-oxidative properties of FAE. Given the broad range of FAE's effects, FAE are now being applied for diseases other than psoriasis. ${ }^{26}$ Favorable effects of off-label use of FAE have been reported for several inflammatory and granulomatous skin diseases, including sarcoidosis, cheilitis granulomatosa, granuloma annulare, necrobiosis lipoidica, and lupus erythematosus. ${ }^{27,28}$ In addition, FAE have been proven to be effective in multiple sclerosis, ${ }^{29,30}$ and FAE became approved as treatment for multiple sclerosis by the FDA and the European Medicines Agency in 2013. Furthermore, FAE are being evaluated for various other diseases, including Huntington disease, myocardial infarction, and asthma. ${ }^{26}$

This review is aimed to give an overview of FAE treatment in the management of psoriasis.

\section{Methods}

This narrative review is based on a literature search in Medline and Embase databases. The search date was performed in January 2014 with an update of the search in July 2014. The following keywords were used: "fumaric acid ester", "dimethylfum*", and "psoria*". There were no restrictions set in year of publication, study type, or language. Furthermore, the FAE sections in the current European, ${ }^{24}$ Dutch, ${ }^{31}$ and German ${ }^{32}$ S3-guidelines on psoriasis treatment were included in this review.

\section{Results \\ Efficacy of FAE}

\section{Randomized controlled trials (RCTs)}

FAE have been shown to be effective in improving moderateto-severe plaque psoriasis in several RCTs. To date, there have been six RCTs that evaluated FAE in psoriasis treatment (Table 1). Two RCTs compared FAE to placebo, ${ }^{13,14}$ one RCT compared two FAE-formulations, ${ }^{33}$ one RCT compared FAE to methotrexate, ${ }^{34}$ one RCT compared the combination of FAE plus a topical vitamin D analog to FAE plus placebo ointment, ${ }^{35}$ and one RCT compared the combination of FAE plus an oral histamine antagonist to FAE plus placebo. ${ }^{36}$ In these RCTs, the total number of psoriasis patients treated with FAE was 320, and the majority of the patients were treated with Fumaderm. Only in the trials of Fallah Arani et al, ${ }^{34}$ Balak et $a l,{ }^{36}$ and of Nieboer et $\mathrm{al}^{33}$ different FAE formulations other than Fumaderm were used. All trials were conducted in Germany ${ }^{13,35}$ or in the Netherlands. ${ }^{14,33-36}$ The treatment duration in the RCTs ranged from 12 to 16 weeks. The largest randomized, placebo-controlled trial was a German multicenter 
Table I Overview of efficacy results of RCTs of fumaric acid esters in psoriasis treatment

\begin{tabular}{|c|c|c|c|c|c|c|}
\hline $\begin{array}{l}\text { Study } \\
\text { (year) }\end{array}$ & Study design & $\begin{array}{l}\text { Study } \\
\text { population }\end{array}$ & Treatment arms & $\begin{array}{l}\text { No of } \\
\text { patients }\end{array}$ & $\begin{array}{l}\text { Treatment } \\
\text { duration in weeks }\end{array}$ & Efficacy results \\
\hline \multirow[t]{2}{*}{$\begin{array}{l}\text { Balak et al } \\
(20 \mid 4)^{36}\end{array}$} & $\begin{array}{l}\text { Single center } \\
\text { double-blind RCT }\end{array}$ & $\begin{array}{l}\text { Moderate-to- } \\
\text { severe psoriasis } \\
\text { PASI }<10\end{array}$ & $\mathrm{FAE}+$ cetirizine & 25 & 12 & $\begin{array}{l}\text { Mean change in PASI - } 65 \% \\
\text { PASI- } 75 \text { response } 20 \%\end{array}$ \\
\hline & & & $\mathrm{FAE}+$ placebo & 25 & 12 & $\begin{array}{l}\text { Mean change in PASI }-66 \% \\
\text { PASI- } 75 \text { response } 20 \%\end{array}$ \\
\hline \multirow[t]{2}{*}{$\begin{array}{l}\text { Fallah Arani } \\
\text { et al }(201 \mathrm{I})^{34}\end{array}$} & Multicenter RCT & $\begin{array}{l}\text { Moderate-to- } \\
\text { severe psoriasis } \\
\text { PASI }<10\end{array}$ & $\begin{array}{l}\text { FAE (Dutch } \\
\text { formulation) }\end{array}$ & 30 & 12 & $\begin{array}{l}\text { Mean change in PASI from } \\
\text { I8.I to } 10.5(-42.0 \%) \\
\text { PASI-75 response } 19 \%\end{array}$ \\
\hline & & & MTX & 30 & 12 & $\begin{array}{l}\text { Mean change in PASI from } \\
\text { I } 4.5 \text { to } 6.7(-53.8 \%) \\
\text { PASI-75 response } 24 \%\end{array}$ \\
\hline \multirow[t]{2}{*}{$\begin{array}{l}\text { Gollnick } \\
\text { et al }(2002)^{35}\end{array}$} & $\begin{array}{l}\text { Multicenter } \\
\text { double-blind RCT }\end{array}$ & Severe psoriasis & $\begin{array}{l}\text { FAE (Fumaderm) + } \\
\text { calcipotriol ointment }\end{array}$ & 68 & 13 & $\begin{array}{l}\text { Mean change in PASI - } \\
76.1 \%\end{array}$ \\
\hline & & & $\begin{array}{l}\text { FAE (Fumaderm) + } \\
\text { placebo ointment }\end{array}$ & 66 & 13 & $\begin{array}{l}\text { Mean change in PASI - } \\
51.9 \%\end{array}$ \\
\hline \multirow[t]{2}{*}{$\begin{array}{l}\text { Altmeyer } \\
\text { et al }(1994)^{13}\end{array}$} & $\begin{array}{l}\text { Multicenter } \\
\text { double-blind RCT }\end{array}$ & $\mathrm{BSA}<10 \%$ & FAE (Fumaderm) & 50 & 16 & $\begin{array}{l}\text { Mean decrease in PASI } \\
\text { from } 21.6 \text { to } 10.8(-50.0 \%)\end{array}$ \\
\hline & & & Placebo & 50 & 16 & Not reported \\
\hline \multirow[t]{2}{*}{$\begin{array}{l}\text { Nieboer } \\
\text { et al }(1990)^{33}\end{array}$} & $\begin{array}{l}\text { Single-center } \\
\text { RCT }\end{array}$ & $\mathrm{BSA}<10 \%$ & FAE (Fumaderm) & 23 & 12 & $\begin{array}{l}\text { More than } 50 \% \\
\text { improvement in } 52 \%\end{array}$ \\
\hline & & & $\begin{array}{l}\text { DMF (Dutch } \\
\text { formulation) }\end{array}$ & II & 12 & $\begin{array}{l}\text { More than } 50 \% \\
\text { improvement in } 45 \%\end{array}$ \\
\hline Nugteren- & Single-center & $\mathrm{BSA}<10 \%$ & FAE (Fumaderm) & 13 & 16 & Mean decrease BSA from \\
\hline Huying et al & $\mathrm{RCT}$ & & & & & $21.0 \%$ to $6.7 \%$ \\
\hline \multirow[t]{2}{*}{$(1990)^{14}$} & & & Octyl FAE & 13 & 16 & Not reported \\
\hline & & & Placebo & 13 & 16 & Not reported \\
\hline
\end{tabular}

Abbreviations: BSA, body surface area affected; DMF, dimethyl fumarate; FAE, fumaric acid esters; MTX, methotrexate; PASI, psoriasis area and severity index; RCT, randomized controlled trial.

study published in 1994, in which 100 patients with plaque psoriasis were randomized 1:1 to receive Fumaderm treatment or placebo for 16 weeks. ${ }^{13} \mathrm{In}$ this RCT, the mean psoriasis area and severity index (PASI) decreased with 50\% from 21.6 at baseline to 10.8 after 16 weeks of FAE treatment. The other placebo-controlled RCT was a small Dutch study published in 1990, in which 39 psoriasis patients were randomized to receive FAE (Fumaderm), octyl fumarate, or placebo. ${ }^{14}$ In contrast to the octyl fumarate and placebo groups, the psoriasis improved significantly in patients treated with Fumaderm with a $68 \%$ reduction in body surface affected from $21 \%$ to $6.7 \%$. In the other four RCTs, mean improvement rates in psoriasis severity of $42 \%-76 \%$ were reported after FAE treatment. The PASI-75 response was reported only in two RCTs and ranged from $19 \%$ to $20 \%$ following $12-16$ weeks of FAE treatment. ${ }^{34,36} \mathrm{~A}$ meta-analysis of the efficacy results of the six RCTs is not feasible due to heterogeneity in efficacy outcomes and incomplete reporting, as some of the earlier RCTs often did not adhere to the current CONSORT guidelines of reporting RCT data. ${ }^{37}$

In the European S3-guidelines on the systemic psoriasis treatment the quality of the evidence of FAE in psoriasis treatment was evaluated. The RCTs of Altmeyer et $\mathrm{al}^{13}$ and Gollnick et $\mathrm{al}^{35}$ were included as $\mathrm{A} 2$ studies (randomized, double-blind clinical study of high quality), while the other RCTs were graded as studies with lesser quality. ${ }^{24}$ Overall, the level of evidence of the efficacy data on FAE was graded as a level 2 of evidence.

\section{Observational studies}

The number of observational studies that evaluated FAE in psoriasis treatment is much larger than the number of RCTs. There have been 29 observational studies published in the period 1987-2014 (Table 2). The majority of these publications were prospective, single center studies. ${ }^{10,11,22,23,38-47}$ There were two prospective, multicenter studies, both were conducted in Germany. ${ }^{48,49}$ The other studies were retrospective multicenter ${ }^{15,50,51}$ or single center studies. ${ }^{19,52-60}$ The majority of the observational studies were uncontrolled. Therefore, the quality of these observational studies is low. The total number of patients treated with FAE in these observational studies combined was 3,119. The majority of studies included patients with moderate-to-severe plaque psoriasis. Two studies evaluated FAE in mild cases of 


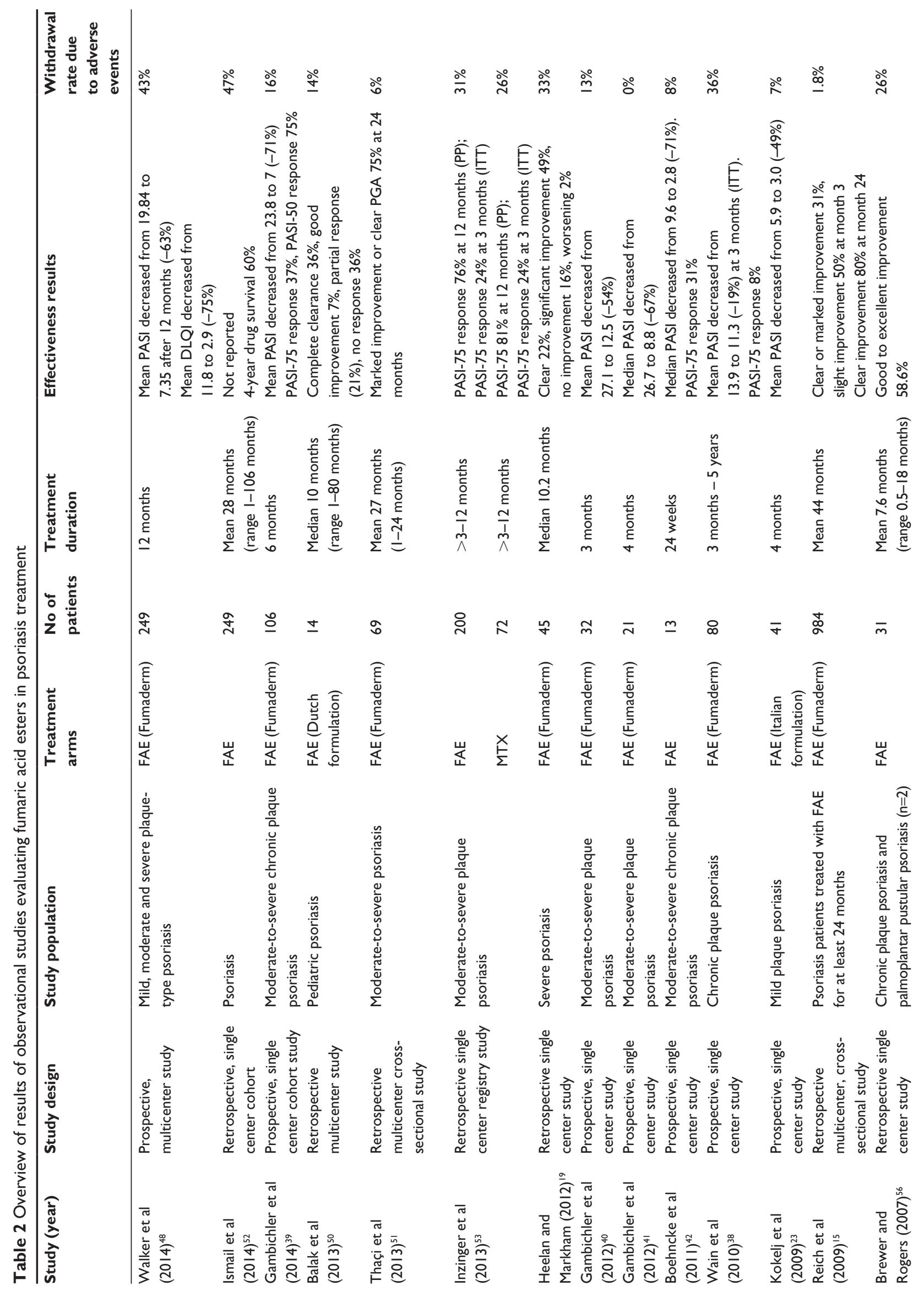




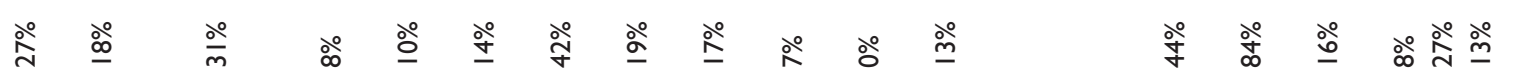
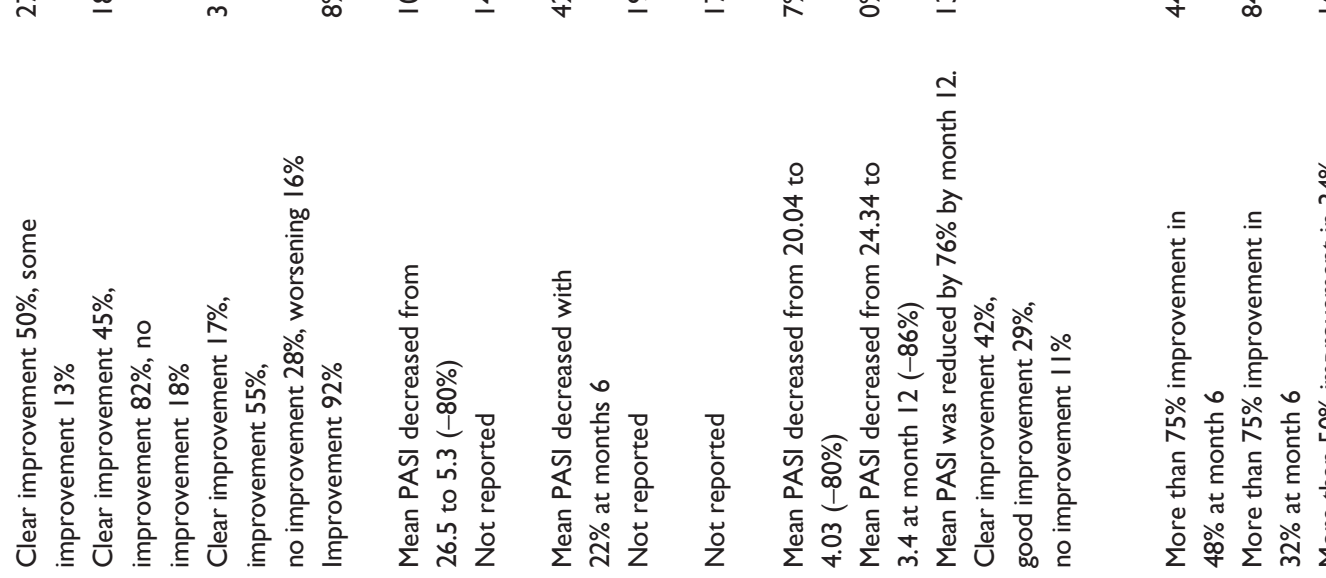

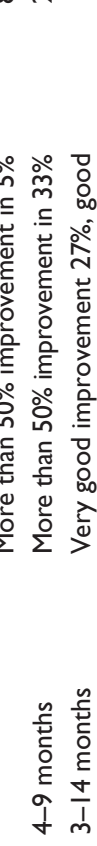

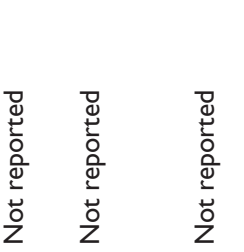

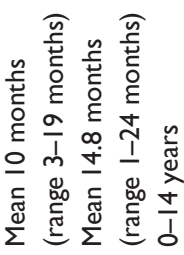

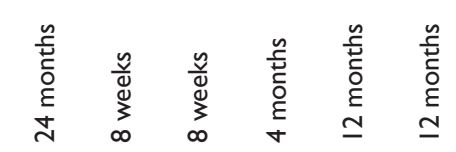

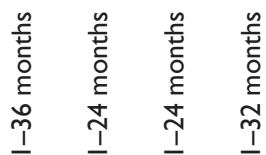

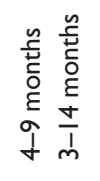

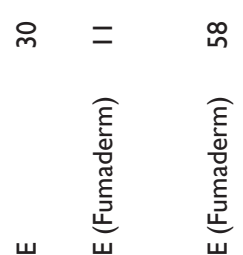

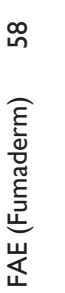

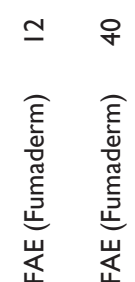

$\because \simeq$
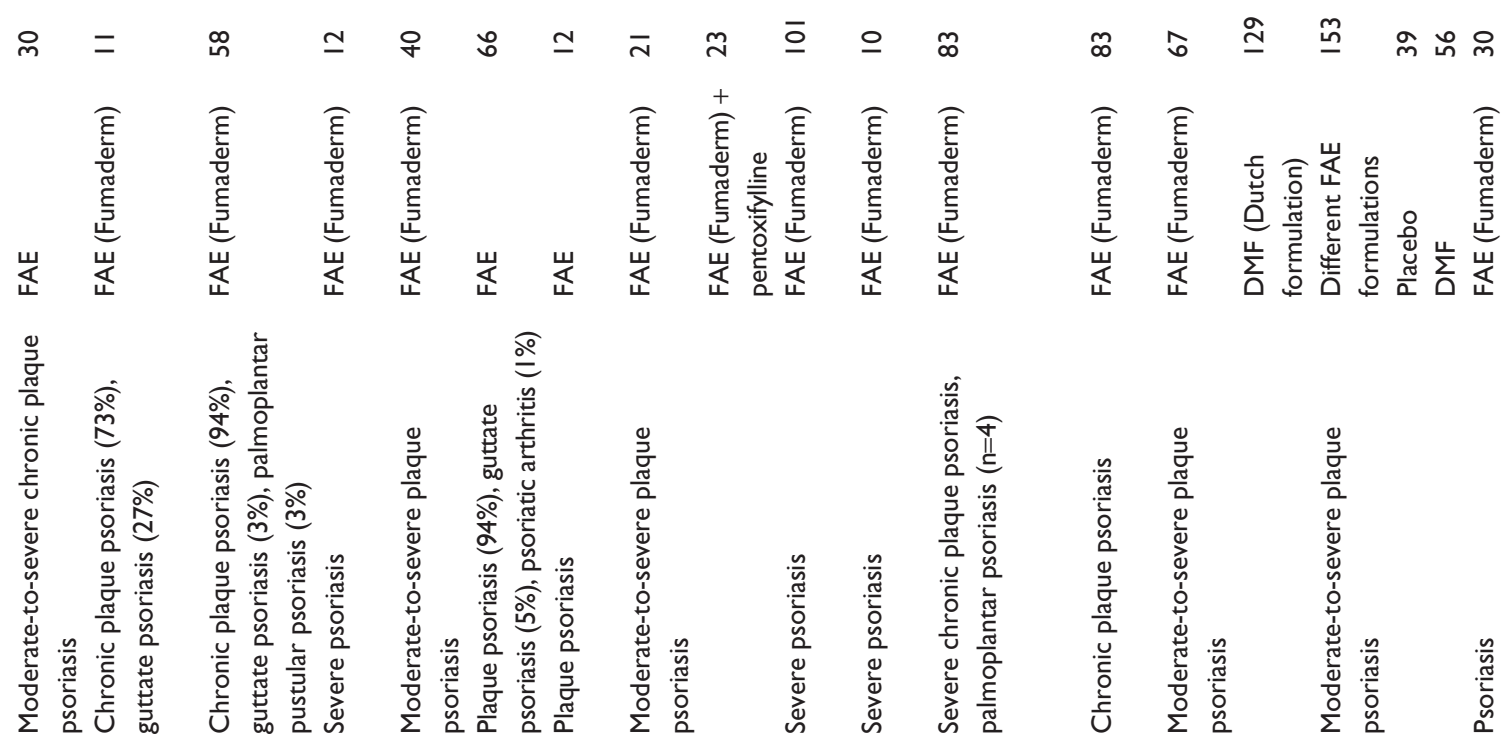

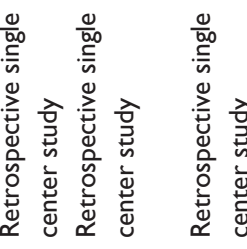
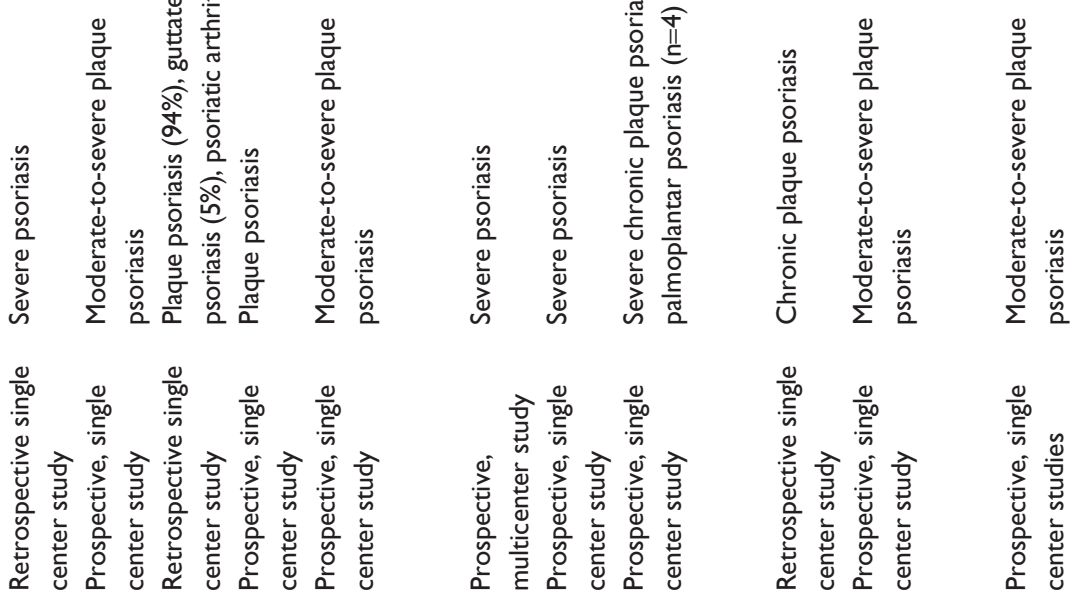

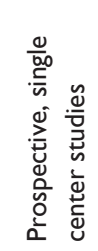

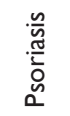

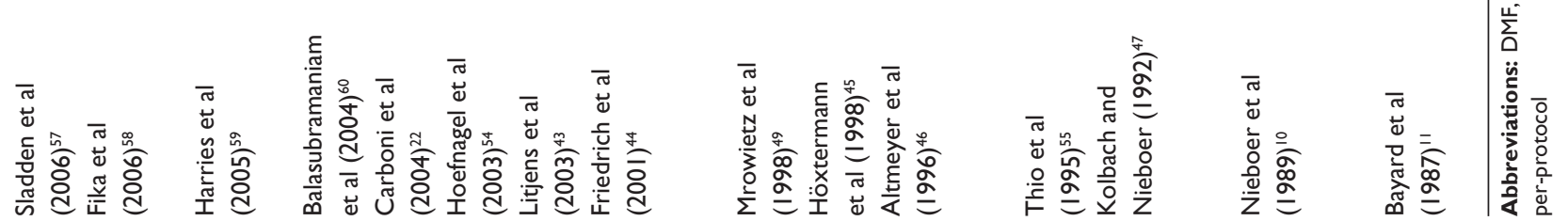


plaque psoriasis. ${ }^{23,48}$ In some studies patients with guttate or palmoplantar pustular psoriasis were included. ${ }^{46,54,56,58,59}$ One study evaluated FAE in children with psoriasis. ${ }^{50}$ The treatment duration ranged from 1 month to 14 years. There were 16 studies that described long-term FAE treatment longer than 12 months up to 14 years. ${ }^{10,11,15,19,22,38,43,47,50-52,54-56,60,61}$ The largest observational study was a retrospective, multicenter study published in $2009 .{ }^{15}$ In this cross-sectional study among 984 psoriasis patients treated with Fumaderm, a large proportion $(82 \%)$ had a marked or clear improvement after 36 months of treatment. Furthermore, there were no major adverse events observed during FAE treatment. The other observational studies also reported favorable effectiveness and safety outcomes of FAE treatment. The results of these studies cannot be easily pooled given that there is heterogeneity in FAE formulations, treatment duration, and treatment outcomes. Mean reductions in PASI ranged from $22 \%$ to $86 \%$. The first clinical effects of FAE are usually seen after week 6 of FAE treatment. Some studies reported PASI-75 responses, which ranged from $8 \%$ to $76 \%$. About $50 \%-70 \%$ of patients achieve at least $75 \%$ reduction in PASI after 16 weeks of treatment. ${ }^{24}$ Studies who applied an intention-to-treat analysis reported lower effectiveness rates that studies that used an as treated analysis, ${ }^{38,53}$ which is a less conservative analysis method than intention-to-treat. ${ }^{62}$

\section{Safety and tolerability of FAE \\ Common subjective adverse events}

The most common adverse events associated with FAE treatment are gastrointestinal complaints and flushing symptoms (Table 3). Gastrointestinal complaints include abdominal cramps, nausea, and diarrhea, and occur in up to $60 \%$ of

Table 3 Summary of common adverse events associated with FAE treatment in psoriasis reported in RCTs and observational studies

\section{Adverse events}

Subjective adverse events

Gastrointestinal complaints

Skin flushing

Pruritus

Headache

Fatigue

Lower extremity edema

Laboratory adverse events

Decrease in lymphocyte count

Increase in eosinophil count

Proteinuria

Increase of serum creatinine

Increase of ASAT/ALAT

Abbreviations: ASAT, aspartate aminotransferase; ALAT, alanine aminotransferase; $R C T$, randomized controlled trial; FAE, fumaric acid esters. patients treated with FAE. ${ }^{24}$ Skin flushing via cutaneous vasodilatation is the second most common adverse event of FAE treatment. In a retrospective analysis of 66 patients who received long-term FAE treatment, skin flushing was the most reported adverse event in $55 \%$ of patients. ${ }^{54}$ Gastrointestinal and flushing symptoms usually occur during the first 3 months of FAE treatment, and then typically decrease over time. ${ }^{63}$

The mechanisms underlying these adverse events during FAE treatment are not fully understood yet, except for the flushing symptoms. Recent experimental studies indicate that FAE-induced skin flushing is mediated by the niacin receptor hydroxycarboxylic acid receptor 2 (HCA2), which was previously known as the $\mathrm{G}$ protein-coupled receptor 109A (GPR109A). Activation of HCA2 leads to flushing symptoms via two different mechanisms. ${ }^{64}$ The early phase of skin flushing is caused by activated HCA2 expressed on epidermal Langerhans cells and selectively induced by cyclooxygenase-1 (COX-1), while the late phase involves HCA2 expressed on keratinocytes and COX-2. ${ }^{65}$

The mechanisms leading to gastrointestinal complaints in FAE treatment are less well understood. One study proposed DMF-induced allergic contact mucositis of the gastrointestinal tract as a cause of gastrointestinal symptoms. ${ }^{66}$ Another study ascribed gastrointestinal complaints during FAE treatment to an eosinophilic gastroenteritis-like syndrome. ${ }^{67}$ Another potential mechanism leading to the gastrointestinal complaints involves FAE-triggered release of tumor necrosis factor alpha $(\mathrm{TNF}-\alpha){ }^{68}$

\section{Common laboratory adverse events}

FAE can be associated with several changes in leukocyte counts. Frequently, a decrease in lymphocyte count is observed during FAE treatment. ${ }^{45} \mathrm{~A}$ reduction of leukocytes can also be seen during FAE treatment. Furthermore, a transient increase in eosinophil count is associated typically with the beginning of FAE treatment. Laboratory adverse events less frequently observed during FAE treatment are an increase in liver enzymes, an increase in serum creatinine, and proteinuria. Proteinuria seems to be associated with dose levels of FAE. ${ }^{69}$ In most cases, proteinuria is fully reversible following dosage reduction or treatment discontinuation. ${ }^{24,69}$

\section{Nephrotoxic adverse events during FAE treatment}

Renal toxicity has been an early concern of FAE treatment as in the 1980s cases have been published of acute renal insufficiency in patients treated with FAE ${ }^{70}$ However, these reports were limited to cases with doses of FAE exceeding 
the maximum daily dosage of $720 \mathrm{mg}$ of DMF currently used. Furthermore, these cases involved the use of topical FAE formulations. It seems likely that the cause of acute renal toxicity in these cases is exposure to too high doses of FAE. Data from RCTs and long-term observational studies so far have not shown an increased risk for acute nephrotoxicity during FAE treatment. ${ }^{38,49,54}$ Haring et al reported the use of beta-2 microglobulin in urine as a sensitive marker to allow early detection of nephrotoxicity during FAE treatment, but this has not been validated in other studies. ${ }^{21}$

Another, more rare, renal adverse event associated with FAE is the development of a drug-induced Fanconi syndrome. Fanconi syndrome is characterized by an increased urine excretion of glucose, amino acids, and phosphate due to proximal tubular damage, which then can lead to hypophosphatemic osteomalacia and complaints of weakness, bone pain, and bone fractures. To date, seven cases have been reported of Fanconi syndrome linked to long-term treatment with FAE. ${ }^{52,71-77}$ In some cases, the symptoms of Fanconi syndrome persisted after FAE discontinuation. ${ }^{21}$ Interestingly, all reported cases of FAE-induced Fanconi syndrome were female patients. The underlying reason for this observation is unknown.

\section{Other adverse events}

Less frequent occurring adverse events during FAE treatment are fatigue, headache, pruritus, and edema of the lower extremities. ${ }^{24}$ In addition, there have been incidental reports of the development of organizing pneumonia, ${ }^{78}$ squamous cell carcinoma, ${ }^{79}$ melanoma, ${ }^{80}$ and Kaposi sarcoma ${ }^{81}$ during FAE treatment. These adverse events could possibly be related to FAE-induced lymphocytopenia. Another important complication of FAE-induced lymphocytopenia is the development of progressive multifocal leukoencephalopathy (PML). There have been two cases published of PML in psoriasis patients treated with FAE. In these two cases the development of PML was linked to exposure to severe low lymphocyte counts for prolonged periods of time..$^{82,83}$

\section{FAE treatment discontinuation due to adverse events} In clinical studies with FAE, $6 \%-40 \%$ of patients discontinued FAE treatment due to intolerable adverse events (Table 2). The most common cause for early treatment discontinuation is intolerable gastrointestinal symptoms and, to a lesser extent, flushing symptoms. Changes in laboratory tests during FAE are usually mild in severity and transient, so that in the majority of cases FAE treatment discontinuation is not necessary. ${ }^{15,24}$

\section{Long-term safety}

The long-term safety profile of FAE therapy is evaluated as favorable. At present, there is no evidence supporting an increased risk for infections, malignancies, or other serious adverse events in patients treated with FAE. There appears to be no significant immunosuppression during long-term FAE treatment. ${ }^{41}$ In a Dutch retrospective single center study in patients treated with FAE continuously for up to 10 to 14 years, there were no serious adverse events or malignancies observed. ${ }^{54}$ Similar safety results were reported in a large, German study among nearly 1,000 patients treated with FAE for a mean duration of 3.5 years. ${ }^{15}$

\section{Improving tolerability of FAE}

In daily clinical practice, several mitigation strategies are pursued to improve the tolerability of FAE. Patient education, the recommendation to take tablets with food or with milk, and temporary dose reduction are typically applied in case of intolerable adverse events. Another option to manage gastrointestinal and flushing symptoms in particular would be to use of pharmacologic treatments, such as aspirin, antihistamines, proton pump inhibitors, and anti-diarrheals. ${ }^{84}$ To date, two RCTs have evaluated the benefit of adding an anti-histamine and aspirin to FAE treatment, respectively. A double-blind, placebo-controlled trial in 50 patients with psoriasis did not show any beneficial effects on the incidence of adverse events of adding the histamine antagonist cetirizine in a daily dose of $10 \mathrm{mg}$ to FAE treatment. ${ }^{36} \mathrm{An}$ RCT among 56 healthy volunteers found that pre-treatment with aspirin reduced the incidence and intensity of flushing symptoms with delayed release DMF. ${ }^{85}$ An uncontrolled case series reported that the addition of montelukast seemed to diminish gastrointestinal complaints. ${ }^{67}$ For the other pharmacological approaches applied to improve FAE's tolerability there is currently no evidence.

\section{Pharmacokinetics and pharmacodynamics of FAE}

There is relatively little data available on the pharmacokinetics of FAE. Following oral administration, DMF is rapidly hydrolyzed in the small intestines into monomethyl fumarate (MMF). ${ }^{86,87}$ Serum levels of MMF rise as would be expected following oral intake of FAE, but DMF levels are undetectable in serum. ${ }^{88,89}$ However, DMF is likely not completely metabolized into MMF in the small intestines. Instead, DMF is able to reach the systemic circulation, and then DMF rapidly enters circulating cells to react and conjugate with intracellular glutathione..$^{90}$ In line, DMF-glutathione 
metabolites were detected in portal veins in rats after DMF administration into the small intestine ${ }^{91}$ and DMF-glutathione metabolites were detected in urine in psoriasis patients who were treated with Fumaderm. ${ }^{92}$

FAE seem to deplete glutathione in circulating immune cells ${ }^{87}$ which induces the expression of the anti-inflammatory protein heme oxygenase 1 (HO-1).$^{93}$ In turn, this results in inhibition of pro-inflammatory cytokine production of TNF$\alpha$, interleukin (IL)-12, and IL-23, which could explain the beneficial response by FAE in psoriasis treatment. ${ }^{93-95}$ The mechanisms of action of FAE in psoriasis have also been ascribed to other immunomodulating effects, including inhibiting the maturation of dendritic cells, ${ }^{96,97}$ inducing T-cell apoptosis, ${ }^{98}$ differentiation of T-helper 2 and T-helper 17 cells, ${ }^{99,100}$ and interfering with leukocyte extravasation by reduction of endothelial adhesion molecule expression. ${ }^{101,102}$ Other studies have shown FAE are capable of inhibiting keratinocyte proliferation ${ }^{103-106}$ and inhibiting angiogenesis by reducing vascular endothelial growth factor receptor-2 expression. ${ }^{107}$

\section{Different FAE-formulations}

There are several different FAE-formulations in use. The only licensed FAE-formulation for psoriasis treatment to date is Fumaderm, which is approved for use in Germany. Fumaderm is a mixture of DMF and the calcium-, magnesium-, and zincsalt of MEF. Two strengths of tablets are available: Fumaderm initial $105 \mathrm{mg}$ tablets containing $30 \mathrm{mg}$ of DMF and $75 \mathrm{mg}$ of MEF-salts; and Fumaderm $215 \mathrm{mg}$ tablets, which contain $120 \mathrm{mg}$ DMF and $95 \mathrm{mg}$ of MEF-salts. DMF is thought to be the active FAE component in Fumaderm treatment. A double-blind study comparing DMF monotherapy with combination therapy of DMF and MEF salts showed no statistically significant differences in efficacy between the two FAE formulations. ${ }^{33}$ In line with these results, experimental studies indicate DMF as the biologically most active FAE. 1,93,96,98

In other European countries, Fumaderm is used as an offlabel drug in the treatment of psoriasis. In the Netherlands, Fumaderm is not easily available. Therefore, several standardized but unlicensed Dutch FAE formulations are in use, containing either DMF and calcium-MEF, DMF, or DMF in slow-release..$^{50,88}$

An FAE-formulation with delayed-release DMF (BG12, also known as Tecfidera, Biogen Idec, Cambridge, MA, USA) was approved for the treatment of relapsing multiple sclerosis in 2013 by the FDA following two successful Phase III studies. ${ }^{29,30}$ The BG-12 FAE-formulation was also in Phase III development for the treatment of psoriasis. ${ }^{108}$ Up to now, this trial has been published only in abstract form. ${ }^{109}$ The development of BG-12 in psoriasis seems to be halted for unknown reasons. ${ }^{10}$ Several large, European RCTs are currently being conducted that evaluate novel FAE-formulations containing only DMF (eg, Clinicaltrials. gov: registration numbers NCT01230138, NCT01726933, and NCT01815723).

In the early 1970 s of FAE treatment, topical FAE were used next to FAE tablets. ${ }^{11}$ A small Dutch double-blind, vehicle-controlled study from 1989 showed no therapeutic effects of topical FAE. ${ }^{10}$ Lack of efficacy of topical FAE was also observed in a German study published in $1993 .{ }^{111}$ Furthermore, topical application of DMF has been associated with local adverse events of erythema and contact urticaria. ${ }^{10,112,113}$ Moreover, DMF is a potent sensitizer that is associated with the development of contact-allergic dermatitis. ${ }^{114,115}$ Therefore, topical treatment with FAE is not recommended. ${ }^{116,117}$

\section{Combination treatment with FAE}

The use of FAE in combination with topical psoriasis treatments is recommended. In a double-blind, vehicle-controlled RCT, the addition of topical calcipotriol led to a faster clinical response to FAE compared to treatment with FAE alone. ${ }^{35}$ In addition, there was a FAE-sparing effect with the combination treatment. The use of FAE in combination with other systemic treatments is currently not recommended, but there are reports of the successful combination of FAE with methotrexate, cyclosporine, acitretin, mycophenolate mofetil, and hydroxyurea. ${ }^{38,60}$ Also, there is anecdotal data on the combination of FAE with biologic treatments such as etanercept. ${ }^{118,119}$ The addition of another systemic therapy to FAE did not result in an increase of adverse events, suggesting that FAE is a good candidate in case combination treatment is needed. FAE may be combined with phototherapy. ${ }^{24}$ A German prospective, multicenter study among 363 psoriasis patients treated with FAE plus phototherapy reported favorable effectiveness and short-term safety up to 1 year for the combination treatment. ${ }^{120}$ Furthermore, the addition of phototherapy may lead to faster responses and may allow the use of FAE in lower dosages. The combination of phototherapy and FAE has also been applied as an off-label treatment for disseminated granuloma annulare. ${ }^{121}$

\section{FAE in special populations}

Most studies published to date included adult patients with moderate-to-severe plaque psoriasis. There is limited 
experience on FAE in children with psoriasis. A retrospective study from the Netherlands described FAE treatment in 14 children with psoriasis. ${ }^{50}$ The effectiveness and safety data in this study were in line with results reported in adult patients. In addition, there have been two case reports on the use of FAE in two children with psoriasis. ${ }^{122,123}$ In elderly psoriasis patients, adjustment in FAE dosages or in treatment titration is not required. ${ }^{24}$

FAE do not seem to be associated with an increased risk of teratogenic effects or adverse pregnancy outcomes. However, given that there is very limited data, FAE are not recommended during pregnancy and lactation. ${ }^{24}$

\section{FAE in other forms of psoriasis}

Most of the current evidence on FAE involves the treatment of chronic plaque psoriasis. There has been some evidence for off-label use of FAE in other clinical forms of psoriasis. A prospective, open label study showed good effects of FAE in improving psoriasis pustulosa palmoplantaris. ${ }^{124}$ In addition, there was a case report of improvement of psoriasis pustulosa generalisata in a 55 -year-old female patient. ${ }^{125}$ There has been a small RCT of FAE in the treatment of psoriatic arthritis, in which minimal improvement of the arthritis was reported. ${ }^{126}$ Furthermore, there have been anecdotal data on improvement of nail psoriasis in patients treated with FAE. ${ }^{49,127}$ The evidence available to date is insufficient to recommend the use of FAE for nail psoriasis and the non-plaque forms of psoriasis.

\section{Guidelines for FAE treatment in psoriasis}

In 1999, Mrowietz et al published guidelines on the use of FAE in psoriasis treatment. ${ }^{63}$ FAE were included and recommended in the European S3-guidelines on the systemic treatment of psoriasis vulgaris, published 10 years later in 2009. ${ }^{24}$ The German ${ }^{32}$ and Dutch ${ }^{31} \mathrm{~S} 3$ guidelines also recommend FAE for psoriasis treatment. The US guidelines included FAE as a second tier systemic agent in psoriasis treatment, given that there is no FDA approved use of FAE. ${ }^{17}$

The recommended indication of FAE is the treatment of moderate-to-severe plaque psoriasis. Contra-indications of FAE treatment are severe gastrointestinal and renal diseases, pregnancy, and breastfeeding.

One of the recommendations regarding FAE is the use of an empirically derived dosing regimen, in which FAE are up titrated within 9 weeks (Table 4). The initial dosage is one tablet of $105 \mathrm{mg}$ (equal to $30 \mathrm{mg}$ of DMF), and the maximum daily dosage is set at six tablets per day of $215 \mathrm{mg}$, which corresponds to $720 \mathrm{mg}$ of DMF. Dosing by body weight is not recommended. The individual dosage of FAE depends
Table 4 The dosing regimen of fumaric acid esters as recommended in the European S3-guidelines on psoriasis treatment. In general, the dosage of fumaric acid esters is increased according to this dosing regimen until a sufficient clinical response is reached

\begin{tabular}{lll}
\hline Week & $\begin{array}{l}\text { No of tablets per day } \\
\text { I05 } \mathbf{~ m g}\end{array}$ & $\begin{array}{l}\text { No of tablets per day } \\
\mathbf{2 1 5} \mathbf{~ m g}\end{array}$ \\
\hline Week I & I & - \\
Week 2 & 2 & - \\
Week 3 & 3 & - \\
Week 4 & - & I \\
Week 5 & - & 2 \\
Week 6 & - & 3 \\
Week 7 & - & 4 \\
Week 8 & - & 5 \\
Week 9 & - & 6 \\
\hline
\end{tabular}

on clinical response and tolerance. In general, the dosage of FAE is increased until a sufficient clinical response is reached. The individual maintenance dose is found by reducing the dose gradually. The mean dosage of FAE is for most patients between two and three tablets of $215 \mathrm{mg}$ per day (Table 5). ${ }^{48}$ In cases of unwanted effects during FAE treatment, dose reduction to dose last tolerated is recommended.

Monitoring and frequent laboratory controls at regular intervals are recommended during FAE treatment. The recommended controls include blood count with leukocyte counts, liver enzymes, serum creatinine, and urine sediment. Treatment discontinuation is recommended in case of a leukocyte count below 3,000 per $\mu \mathrm{L}$ or a lymphocyte count below 500 per $\mu \mathrm{L} . .^{24,128}$

Table 5 Summary of clinical response and recommendations regarding $F A E$ in the treatment of plaque psoriasis

\begin{tabular}{ll}
\hline No of studies & Six RCTs, 29 observational studies, \\
& 3,439 patients \\
PASI-75 response at week I6 & $50 \%-70 \%$ of patients \\
Withdrawal rate due to & $6 \%-40 \%$ of patients \\
adverse events & \\
Speed of onset & First clinical response week 6 of treatment \\
Indications & Moderate-to-severe plaque psoriasis \\
Contra-indications & Severe gastrointestinal disease, severe \\
& renal disease, pregnancy, and lactation \\
Maximum dosage & Six tablets 2I5 mg per day (720 mg DMF) \\
Mean dosage & One to three tablets 2I5 mg per day \\
& (I20-360 mg DMF) \\
Common adverse events & Gastrointestinal complaints, flushing, \\
& lymphocytopenia, eosinophilia, and \\
& proteinuria \\
Monitoring & Leukocyte counts, serum creatinine, \\
Drug interactions & ASAT/ALAT, and urinalysis \\
\hline
\end{tabular}

Abbreviations: ASAT, aspartate aminotransferase; ALAT, alanine aminotransferase; DMF, dimethyl fumarate; FAE, fumaric acid esters; RCTs, randomized controlled trials; PASI, psoriasis area and severity index. 
The use of concomitant topical treatments is recommended to allow for faster treatment responses and a possible FAE sparing effect. ${ }^{35}$ Combinations of FAE with other systemic treatments cannot be completely recommended due to lack of experience. However, because FAE do not have significant immunosuppressive effects, FAE may be preferable over other systemic treatments in case of combination treatment. There are no known drug interactions of FAE. FAE are not metabolized by common pathways such as cytochrome P450. ${ }^{63}$ In a retrospective analysis of 69 psoriasis patients treated with FAE and who required at least one medication for a comorbid condition, there were no reports of any drug interactions. ${ }^{51}$ The guidelines do recommend to avoid concomitant use of FAE with drugs with potential nephrotoxic effects.

\section{FAE in psoriasis patients with concomitant diseases}

FAE are efficacious in various inflammatory diseases other than psoriasis, ${ }^{26,28}$ and therefore FAE may be suitable to treat psoriasis patients with certain concomitant diseases. One example is multiple sclerosis, for which FAE became approved by the FDA for the treatment of relapsing forms of multiple sclerosis. FAE may be the treatment of choice in the rare cases in which psoriasis co-occur with multiple sclerosis, ${ }^{129}$ and in cases of patients with multiple sclerosis in which psoriasis is provoked by treatments like interferon-beta. ${ }^{130,131}$

There have been a few case reports that demonstrated improvement of cutaneous forms of lupus erythematosus with off-label use of FAE treatment. ${ }^{28,132}$ FAE may potentially be helpful in the treatment of patients presenting simultaneously with both psoriasis and cutaneous lupus erythematosus. The coexistence of psoriasis and lupus erythematosus, however, is very rare. ${ }^{133}$

There is some evidence suggesting that FAE may positively influence cardiovascular and metabolic comorbidities via their anti-inflammatory and anti-oxidative properties. Recent pre-clinical studies found that DMF has cardioprotective effects, ${ }^{134}$ and that FAE exhibited ameliorating effects in an animal model of metabolic disturbances. ${ }^{135}$ FAE could have similar effects in psoriasis patients. A small, uncontrolled observational study in 13 psoriasis patients treated with FAE reported an improvement of endothelial vasodilator function, a decrease of insulin resistance, and beneficial changes in several serum proteins levels, including C-reactive protein and adiponectin. ${ }^{42} \mathrm{~A}$ potential cardioprotective treatment effect as measured by oral glucose tolerance tests, serum inflammation markers, and adipokines was observed in a larger clinical study involving 42 patients treated for 24 weeks with FAE or other systemic psoriasis treatments. ${ }^{61}$

FAE have been proposed as an adjunctive treatment to anti-retroviral therapy to treat HIV and HIV-associated neurodegeneration on the basis of the anti-oxidative and neuroprotective properties of FAE. ${ }^{136}$ In an experimental study, DMF attenuated HIV-associated neurotoxicity and suppressed replication of HIV in HIV-infected macrophages. ${ }^{137}$ Although clinical data are so far not available, FAE could potentially be a treatment of choice in psoriasis patients with concomitant HIV infection.

\section{Comparison of FAE to other systemic psoriasis treatments}

To date, FAE have only been compared directly to methotrexate. A Dutch multicenter, RCT compared the short-term efficacy of FAE to that of methotrexate and found no statistically significant differences in PASI improvement after 16 weeks of treatment in 60 patients with moderate-to-severe plaque psoriasis. ${ }^{34}$ A retrospective registry study from Austria involving 272 patients with moderate-to-severe psoriasis found similar effectiveness of FAE and methotrexate in daily clinical practice. ${ }^{53}$ There are no other head-to-head comparisons with FAE to any of the other systemic or biologic treatments published to date.

In a meta-analysis of RCT data that was published in 2008, FAE appeared to have similar efficacy compared to etanercept (50 mg twice weekly) and to be more efficacious than efalizumab. ${ }^{138}$ Furthermore, in this meta-analysis, FAE had the highest withdrawal rate due to adverse events. The meta-analysis had included only the 1994 RCT of Altmeyer et al. ${ }^{13}$ An updated meta-analysis published in 2014 found that FAE were equally effective compared to methotrexate with a risk difference of 0.05 (95\% confidence interval -0.18 to 0.27$){ }^{139}$

\section{Position of FAE in psoriasis treatment landscape}

Psoriasis is a common, chronic, immune-mediated inflammatory skin disease that can have a major impact on patient's quality of life. ${ }^{140}$ Most patients with moderate-to-severe plaque psoriasis require systemic treatment to control the disease. The options for systemic treatment of psoriasis available to date are: photo(chemo)therapy with ultraviolet (UV) A or UVB; conventional treatments, which include methotrexate, cyclosporine, FAE, and acitretin; and biologic treatments, which include anti-TNF- $\alpha$ inhibitors (etanercept, infliximab, and adalimumab) and an IL-12/23 inhibitor 
(ustekinumab). Given that psoriasis is a chronic disease, patients with psoriasis often need long-term treatment. Long-term use of systemic treatments, however, can be restricted because of issues of toxicity. ${ }^{141}$ Therefore, rotational treatment and combination treatment are usually pursued to reduce toxicity of systemic psoriasis treatments. ${ }^{142}$ Next to efficacy and safety, cost-effectiveness is another important consideration in the evaluation of psoriasis treatments. ${ }^{143}$

When comparing the safety profiles of the conventional drugs, FAE may have the most favorable long-term safety profile and may therefore be preferred over methotrexate, acitretin, and cyclosporine. ${ }^{141}$ However, direct comparisons between these systemic treatments are difficult to make given that head-to-head studies are lacking. When comparing the efficacy responses, FAE seems to be equally effective compared to methotrexate. ${ }^{34,139}$

In Germany and the Netherlands, FAE are regarded as a suitable first-line treatment for moderate-to-severe plaque psoriasis. ${ }^{31,32}$ In contrast, globally methotrexate is regarded as the standard first-line systemic treatment for psoriasis. ${ }^{144}$ The fact that FAE are still unlicensed and that clinical inexperience with FAE treatment is limited are two major barriers in the use of FAE. To improve the use of FAE, long-term comparisons of FAE and methotrexate are needed. ${ }^{144,145}$

\section{Conclusion}

FAE have been used for the systemic treatment of psoriasis since 1959. The development of FAE as a psoriasis treatment was largely empirical and did not follow the conventional drug development phases. Experimental studies from the last two decades have shown that FAE exert immunomodulating, anti-inflammatory, anti-oxidative, and anti-proliferative effects. Currently, FAE are approved only in Germany for the treatment of moderate-to-severe psoriasis. However, FAE are increasingly being used as an unlicensed treatment in several other European countries.

To date, FAE have been evaluated in six RCTs and 29 observational studies in a combined total number of 3,439 patients. About 50\%-70\% achieve at least a $75 \%$ improvement in PASI following 12 to 16 weeks of treatment. Gastrointestinal and flushing symptoms are major limitations of FAE treatment, given that up to $40 \%$ need to discontinue FAE treatment due to intolerable adverse events. Lymphocytopenia, eosinophilia, and proteinuria are commonly observed during FAE treatment, rarely require treatment discontinuation, but should be monitored during FAE treatment. Long-term FAE treatment is not associated with an increased risk for infections, malignancies, or other serious adverse events. There is some evidence that suggest that FAE may positively influence cardiovascular comorbidities and concomitant inflammatory diseases.

The 2009 European S3-guidelines on psoriasis treatment recommends FAE as a systemic treatment for moderateto-severe plaque psoriasis with a favorable risk-benefit ratio. The use of FAE in the treatment of psoriasis could be improved with approval by regulatory agencies, optimization of the FAE formulation and treatment tolerability, and longterm comparison to other systemic psoriasis treatments.

\section{Disclosure}

The author reports no conflicts of interest in this work.

\section{References}

1. Mrowietz U, Asadullah K. Dimethylfumarate for psoriasis: more than a dietary curiosity. Trends Mol Med. 2005;11(1):43-48.

2. Raimundo N, Baysal BE, Shadel GS. Revisiting the TCA cycle: signaling to tumor formation. Trends Mol Med. 2011;17(11):641-649.

3. Schweckendiek W. [Treatment of psoriasis vulgaris] Heilung von Psoriasis vulgaris. Med Monatsschr. 1959;13(2):103-104.

4. Schweckendiek W. Behandlung von psoriasis mit lipoidloslichen fumarsaureverbindungen. Medizin Heute. 1966;15:219-220.

5. Schafer G. Fumarsaure lindert die schuppenflechte. Selecta. 1984;15: 1260-1261.

6. van Dijk E. [Fumaric acid in the treatment of patients with psoriasis] Fumaarzuur voor de behandeling van patienten met psoriasis. Ned Tijdschr Geneeskd. 1985;129(11):485-486.

7. Dubiel W, Happle R. [Experimental treatment with fumaric acid monoethylester in psoriasis vulgaris] Behandlungsversuch mit Fumarsauremonoathylester bei Psoriasis vulgaris. Z Haut Geschlechtskr. 1972;47(13):545-550.

8. Braun-Falco O. [Letter: Fumaric acid in psoriasis vulgaris] Fumarsaure bei Psoriasis vulgaris. Dtsch Med Wochenschr. 1974;99(18): 977-978.

9. Raab W. [Psoriasis therapy with fumaric acid and fumaric acid esters] Psoriasis-Behandlung mit Fumarsaure und Fumarsaureestern. Z Hautkr. 1984;59(10):671-679.

10. Nieboer C, de Hoop D, van Loenen AC, Langendijk PN, van Dijk E. Systemic therapy with fumaric acid derivates: new possibilities in the treatment of psoriasis. J Am Acad Dermatol. 1989;20(4): 601-608.

11. Bayard W, Hunziker T, Krebs A, Speiser P, Joshi R. [Peroral longterm treatment of psoriasis using fumaric acid derivatives] Perorale Langzeitbehandlung der Psoriasis mit Fumarsaurederivaten. Hautarzt. 1987;38(5):279-285.

12. Kunst L. Psoriasis behandeling. Ned Tijdschr Int Geneesknd. 1985; 7(16):24-29.

13. Altmeyer PJ, Matthes U, Pawlak F, et al. Antipsoriatic effect of fumaric acid derivatives. Results of a multicenter double-blind study in 100 patients. J Am Acad Dermatol. 1994;30(6):977-981.

14. Nugteren-Huying WM, van der Schroeff JG, Hermans J, Suurmond D. Fumaric acid therapy for psoriasis: a randomized, double-blind, placebocontrolled study. J Am Acad Dermatol. 1990;22(2 pt 1):311-312.

15. Reich K, Thaci D, Mrowietz U, Kamps A, Neureither M, Luger T. Efficacy and safety of fumaric acid esters in the long-term treatment of psoriasis - a retrospective study (FUTURE). J Dtsch Dermatol Ges. 2009;7(7):603-611.

16. Augustin M, Spehr C, Radtke MA, et al. German psoriasis registry PsoBest: objectives, methodology and baseline data. J Dtsch Dermatol Ges. 2014;12(1):48-57. 
17. Menter A, Korman NJ, Elmets CA, et al. Guidelines of care for the management of psoriasis and psoriatic arthritis: section 4. Guidelines of care for the management and treatment of psoriasis with traditional systemic agents. J Am Acad Dermatol. 2009;61(3):451-485.

18. Anstey AV. Fumaric acid esters in the treatment of psoriasis. $\mathrm{Br} J$ Dermatol. 2010;162(2):237-238.

19. Heelan K, Markham T. Fumaric acid esters as a suitable first-line treatment for severe psoriasis: an Irish experience. Clin Exp Dermatol. 2012;37(7):793-795.

20. Fallah Arani S, Balak DM, Neumann HA, Kuipers MV, Thio HB. Treatment of psoriasis with non-registered fumaric acid esters in The Netherlands: a nationwide survey among Dutch dermatologists. J Eur Acad Dermatol Venereol. 2014;28(7):972-975.

21. Haring N, Mahr HS, Mundle M, Strohal R, Lhotta K. Early detection of renal damage caused by fumaric acid ester therapy by determination of urinary beta2-microglobulin. Br J Dermatol. 2011;164(3):648-651.

22. Carboni I, De Felice C, De Simoni I, Soda R, Chimenti S. Fumaric acid esters in the treatment of psoriasis: an Italian experience. J Dermatolog Treat. 2004;15(1):23-26.

23. Kokelj F, Plozzer C, Avian A, Trevisan G. Fumaric acid and its derivatives in the treatment of psoriasis vulgaris: our experience in forty-one patients. Acta Dermatovenerol Croat. 2009;17(3):170-175.

24. Pathirana D, Ormerod AD, Saiag P, et al. European S3-guidelines on the systemic treatment of psoriasis vulgaris. $J$ Eur Acad Dermatol Venereol. 2009;23(suppl 2):1-70.

25. Arbiser JL. Fumarate esters as angiogenesis inhibitors: key to action in psoriasis? J Invest Dermatol. 2011;131(6):1189-1191.

26. Meissner M, Valesky EM, Kippenberger S, Kaufmann R. Dimethyl fumarate - only an anti-psoriatic medication? J Dtsch Dermatol Ges. 2012;10(11):793-801.

27. Breuer K, Gutzmer R, Volker B, Kapp A, Werfel T. Therapy of noninfectious granulomatous skin diseases with fumaric acid esters. $\mathrm{BrJ}$ Dermatol. 2005;152(6):1290-1295.

28. Klein A, Coras B, Landthaler M, Babilas P. Off-label use of fumarate therapy for granulomatous and inflammatory skin diseases other than psoriasis vulgaris: a retrospective study. J Eur Acad Dermatol Venereol. 2012;26(11):1400-1406.

29. Gold R, Kappos L, Arnold DL, et al. Placebo-controlled phase 3 study of oral BG-12 for relapsing multiple sclerosis. N Engl J Med. 2012; 367(12):1098-1107.

30. Fox RJ, Miller DH, Phillips JT, CONFIRM Study Investigators, et al. Placebo-controlled phase 3 study of oral BG-12 or glatiramer in multiple sclerosis. N Engl J Med. 2012;367(12):1087-1097.

31. Zweegers J, de Jong EM, Nijsten TE, et al. Summary of the Dutch S3-guidelines on the treatment of psoriasis 2011. Dermatol Online J. 2014;20(3):ii:doj_21769.

32. Nast A, Boehncke WH, Mrowietz U, et al. S3 - guidelines on the treatment of psoriasis vulgaris (English version). Update. $J$ Dtsch Dermatol Ges. 2012;10(2):S1-S95.

33. Nieboer C, de Hoop D, Langendijk PN, van Loenen AC, Gubbels J. Fumaric acid therapy in psoriasis: a double-blind comparison between fumaric acid compound therapy and monotherapy with dimethylfumaric acid ester. Dermatologica. 1990;181(1):33-37.

34. Fallah Arani S, Neumann H, Hop WC, Thio HB. Fumarates vs methotrexate in moderate to severe chronic plaque psoriasis: a multicentre prospective randomized controlled clinical trial. Br J Dermatol. 2011;164(4):855-861.

35. Gollnick H, Altmeyer P, Kaufmann R, et al. Topical calcipotriol plus oral fumaric acid is more effective and faster acting than oral fumaric acid monotherapy in the treatment of severe chronic plaque psoriasis vulgaris. Dermatology. 2002;205(1):46-53.

36. Balak DM, Fallah-Arani S, Venema CM, Neumann HA, Thio HB. Addition of an oral histamine antagonist to reduce adverse events associated with fumaric acid esters in the treatment of psoriasis: a randomized doubleblind placebo-controlled trial. Br J Dermatol. Epub 2014 July 17.

37. Schulz KF, Altman DG, Moher D, Group C. CONSORT 2010 statement: updated guidelines for reporting parallel group randomised trials. $B M J$. 2010;340:c332.
38. Wain EM, Darling MI, Pleass RD, Barker JN, Smith CH. Treatment of severe, recalcitrant, chronic plaque psoriasis with fumaric acid esters: a prospective study. Br J Dermatol. 2010;162(2):427-434.

39. Gambichler T, Kreuter A, Susok L, et al. Glutathione-S-transferase T1 genotyping and phenotyping in psoriasis patients receiving treatment with oral fumaric acid esters. J Eur Acad Dermatol Venereol. 2014;28(5):574-580.

40. Gambichler T, Bechara FG, Scola N, Rotterdam S, Altmeyer P, Skrygan M. Serum levels of antimicrobial peptides and proteins do not correlate with psoriasis severity and are increased after treatment with fumaric acid esters. Arch Dermatol Res. 2012;304(6):471-474.

41. Gambichler T, Scola N, Rotterdam S, et al. Monitoring peripheral blood CD4(+) intracellular adenosine triphosphate concentration in patients with psoriasis treated with fumaric acid esters. Acta Derm Venereol. 2012;92(4):364-366.

42. Boehncke S, Fichtlscherer S, Salgo R, et al. Systemic therapy of plaque-type psoriasis ameliorates endothelial cell function: results of a prospective longitudinal pilot trial. Arch Dermatol Res. 2011;303(6): 381-388.

43. Litjens NH, Nibbering PH, Barrois AJ, et al. Beneficial effects of fumarate therapy in psoriasis vulgaris patients coincide with downregulation of type 1 cytokines. Br J Dermatol. 2003;148(3):444-451.

44. Friedrich M, Sterry W, Klein A, Ruckert R, Docke WD, Asadullah K. Addition of pentoxifylline could reduce the side effects of fumaric acid esters in the treatment of psoriasis. Acta Derm Venereol. 2001;81(6): 429-430.

45. Höxtermann S, Nuchel C, Altmeyer P. Fumaric acid esters suppress peripheral CD4- and CD8-positive lymphocytes in psoriasis. Dermatology. 1998;196(2):223-230.

46. Altmeyer P, Hartwig R, Matthes U. [Efficacy and safety profile of fumaric acid esters in oral long-term therapy with severe treatment refractory psoriasis vulgaris. A study of 83 patients] Das Wirkuns- und Sicherheitsprofil von Fumarsaureestern in der oralen Langzeittherapie bei schwerer therapieresistenter Psoriasis vulgaris. Eine Untersuchung an 83 Patienten. Hautarzt. 1996;47(3):190-196.

47. Kolbach DN, Nieboer C. Fumaric acid therapy in psoriasis: results and side effects of 2 years of treatment. J Am Acad Dermatol. 1992; 27(5 pt 1):769-771.

48. Walker F, Adamczyk A, Kellerer C, et al. Fumaderm in daily practice for psoriasis - dosing, efficacy and quality of life. Br J Dermatol. Epub 2014 May 10.

49. Mrowietz U, Christophers E, Altmeyer P. Treatment of psoriasis with fumaric acid esters: results of a prospective multicentre study. German Multicentre Study. Br J Dermatol. 1998;138(3):456-460.

50. Balak DM, Oostveen AM, Bousema MT, et al. Effectiveness and safety of fumaric acid esters in children with psoriasis: a retrospective analysis of 14 patients from The Netherlands. Br J Dermatol. 2013;168(6): 1343-1347.

51. Thaçi D, Weisenseel P, Philipp S, et al. Efficacy and safety of fumaric acid esters in patients with psoriasis on medication for comorbid conditions - a retrospective evaluation (FACTS). J Dtsch Dermatol Ges. 2013;11(5):429-435.

52. Ismail N, Collins P, Rogers S, Kirby B, Lally A. Drug survival of fumaric acid esters for psoriasis: a retrospective study. $\mathrm{Br} J$ Dermatol. 2014;171(2):397-402.

53. Inzinger $\mathrm{M}$, Weger $\mathrm{W}$, Heschl $\mathrm{B}$, Salmhofer $\mathrm{W}$, Quehenberger F, Wolf $\mathrm{P}$. Methotrexate vs fumaric acid esters in moderate-to-severe chronic plaque psoriasis: data registry report on the efficacy under daily life conditions. J Eur Acad Dermatol Venereol. 2013;27(7):861-866.

54. Hoefnagel JJ, Thio HB, Willemze R, Bouwes Bavinck JN. Long-term safety aspects of systemic therapy with fumaric acid esters in severe psoriasis. Br J Dermatol. 2003;149(2):363-369.

55. Thio HB, Van Der Schroeff JG, Nugteren-Huying WM, Vermeer BJ. Long-term systemic therapy with dimethylfumarate and monoethylfumarate (Fumaderm) in psoriasis. J Eur Acad Dermatol Venereol. 1995;4(1):35-40.

56. Brewer L, Rogers S. Fumaric acid esters in the management of severe psoriasis. Clin Exp Dermatol. 2007;32(3):246-249. 
57. Sladden MJ, Osborne JE, Hutchinson PE. Fumaric acid esters for severe psoriasis: the Leicestershire experience. Br J Dermatol. 2006;155(4): 843-844.

58. Fika Z, Williams RE, Williamson DJ. Fumaric acid esters in psoriasis. Br J Dermatol. 2006;154(3):567-568.

59. Harries MJ, Chalmers RJ, Griffiths CE. Fumaric acid esters for severe psoriasis: a retrospective review of 58 cases. Br J Dermatol. 2005; 153(3):549-551.

60. Balasubramaniam P, Stevenson O, Berth-Jones J. Fumaric acid esters in severe psoriasis, including experience of use in combination with other systemic modalities. Br J Dermatol. 2004;150(4):741-746.

61. Boehncke S, Salgo R, Garbaraviciene J, et al. Effective continuous systemic therapy of severe plaque-type psoriasis is accompanied by amelioration of biomarkers of cardiovascular risk: results of a prospective longitudinal observational study. J Eur Acad Dermatol Venereol. 2011;25(10):1187-1193.

62. van Lumig PP, Driessen RJ, Kievit W, Boezeman JB, van de Kerkhof PC, de Jong EM. Results of three analytical approaches on long-term efficacy of etanercept for psoriasis in daily practice. J Am Acad Dermatol. 2013;68(1):57-63.

63. Mrowietz U, Christophers E, Altmeyer P. Treatment of severe psoriasis with fumaric acid esters: scientific background and guidelines for therapeutic use. The German Fumaric Acid Ester Consensus Conference. Br J Dermatol. 1999;141(3):424-429.

64. Hanson J, Gille A, Offermanns S. Role of HCA(2) (GPR109A) in nicotinic acid and fumaric acid ester-induced effects on the skin. Pharmacol Ther. 2012;136(1):1-7.

65. Hanson J, Gille A, Zwykiel S, et al. Nicotinic acid- and monomethyl fumarate-induced flushing involves GPR109A expressed by keratinocytes and COX-2-dependent prostanoid formation in mice. J Clin Invest. 2010;120(8):2910-2919.

66. Hessam S, Altmeyer P, Stucker M, Dickel H. Dimethylfumarate in the treatment of psoriasis - a hitherto unnoticed source of sensitization? A case series and review of the literature. Allergologie. 2013;36(1): 19-27.

67. Tornatore C, Amjad F. Attenuation of dimethyl fumarate-related gastrointestinal symptoms with montelukast. Neurology. 2014;82(10) Supplement P7.251.

68. Asadullah K, Schmid H, Friedrich M, et al. Influence of monomethylfumarate on monocytic cytokine formation - explanation for adverse and therapeutic effects in psoriasis? Arch Dermatol Res. 1997;289(11): 623-630.

69. Ogilvie S, Lewis Jones S, Dawe R, Foerster J. Proteinuria with fumaric acid ester treatment for psoriasis. Clin Exp Dermatol. 2011;36(6): 632-634

70. Roodnat J, Christiaans MH, Nugteren-Huying WM, van der Schroeff JG, Chang PC. [Acute kidney insufficiency in patients treated with fumaric acid esters for psoriasis] Acute nierinsufficientie bij patienten behandeld met fumaarzuuresters wegens psoriasis. Ned Tijdschr Geneeskd. 1989;133(52):2623-2626.

71. Boesken WH, Oser B, Roth J, Wedekind S, Wokalek H. Nephrotoxic effects of fumaric acid therapy of psoriasis. Nieren- und Hochdruckkrankheiten. 1998;27(3):145-150.

72. Fliegner L, Spiegel P. [Osteomalacia as an apparently rare side effect of oral fumaric acid therapy. Secondary DeToni-Debre Fanconi syndrome in the adult] Osteomalazie als offenbar seltene Nebenwirkung der oralen Fumarsauretherapie. Sekundares DeToni-Debre Fanconi-Syndrom des Erwachsenen. Hautarzt. 1992;43(9):554-560.

73. Schilling S, Goelz S, Linker R, Luehder F, Gold R. Fumaric acid esters are effective in chronic experimental autoimmune encephalomyelitis and suppress macrophage infiltration. Clin Exp Immunol. 2006;145(1):101-107.

74. Raschka C, Koch HJ. Longterm treatment of psoriasis using fumaric acid preparations can be associated with severe proximal tubular damage. Hum Exp Toxicol. 1999;18(12):738-739.

75. Warzecha J, Runck A, Priepke E, Storm H, Weigand H. Multiple pathological fractures in acquired Fanconi's syndrome after treatment of psoriasis with fumaric acid. Unfallchirurg. 2001;104(5):448-451.
76. Haviv YS, Zimmerman M, Berkman N, Safadi R. Fumaric acid esterinduced diffuse renal tubular injury presenting as Fanconi syndrome and osteomalacia. Clin Drug Investig. 1999;17(4):333-335.

77. Reid C, Holian J, Kane D, Kirby B. De Toni-Fanconi syndrome secondary to fumaric acid esters. Br J Dermatol. 2013;169((Reid C.; Kirby B.) Department of Dermatology, St Vincent's University Hospital, Dublin, Ireland):24.

78. Deegan AP, Kirby B, Rogers S, Crotty TB, McDonnell TJ. Organising pneumonia associated with fumaric acid ester treatment for psoriasis. Clin Respir J. 2010;4(4):248-251.

79. Jennings L, Murphy G. Squamous cell carcinoma as a complication of fumaric acid ester immunosuppression. J Eur Acad Dermatol Venereol. 2009;23(12):1451.

80. Barth D, Simon JC, Wetzig T. Malignant melanoma during treatment with fumaric acid esters - coincidence or treatment-related? J Dtsch Dermatol Ges. 2011;9(3):223-225.

81. Philipp S, Kokolakis G, Hund M, et al. Immunological changes in psoriasis patients under long-term treatment with fumaric acid esters: risk of Kaposi sarcoma occurrence? Eur J Dermatol. 2013;23(3):339-343.

82. Ermis U, Weis J, Schulz JB. PML in a patient treated with fumaric acid. N Engl J Med. 2013;368(17):1657-1658.

83. van Oosten BW, Killestein J, Barkhof F, Polman CH, Wattjes MP. PML in a patient treated with dimethyl fumarate from a compounding pharmacy. N Engl J Med. 2013;368(17):1658-1659.

84. Phillips JT, Hutchinson M, Fox R, Gold R, Havrdova E. Managing flushing and gastrointestinal events associated with delayed-release dimethyl fumarate: experiences of an international panel. Mult Scler Relat Disord. 2014;3(4):513-519.

85. Sheikh SI, Nestorov I, Russell H, et al. Tolerability and pharmacokinetics of delayed-release dimethyl fumarate administered with and without aspirin in healthy volunteers. Clin Ther. 2013;35(10):1582.e9-1594.e9.

86. Werdenberg D, Joshi R, Wolffram S, Merkle HP, Langguth P. Presystemic metabolism and intestinal absorption of antipsoriatic fumaric acid esters. Biopharm Drug Dispos. 2003;24(6):259-273.

87. Litjens NH, van Strijen E, van Gulpen C, et al. In vitro pharmacokinetics of anti-psoriatic fumaric acid esters. BMC Pharmacol. 2004;4:22.

88. Litjens NH, Burggraaf J, van Strijen E, et al. Pharmacokinetics of oral fumarates in healthy subjects. Br J Clin Pharmacol. 2004;58(4):429-432.

89. Rostami-Yazdi M, Clement B, Mrowietz U. Pharmacokinetics of antipsoriatic fumaric acid esters in psoriasis patients. Arch Dermatol Res. 2010;302(7):531-538.

90. Schmidt TJ, Ak M, Mrowietz U. Reactivity of dimethyl fumarate and methylhydrogen fumarate towards glutathione and N-acetyl-L-cysteine - preparation of S-substituted thiosuccinic acid esters. Bioorg Med Chem. 2007;15(1):333-342.

91. Dibbert S, Clement B, Skak-Nielsen T, Mrowietz U, Rostami-Yazdi M. Detection of fumarate-glutathione adducts in the portal vein blood of rats: evidence for rapid dimethylfumarate metabolism. Arch Dermatol Res. 2013;305(5):447-451.

92. Rostami-Yazdi M, Clement B, Schmidt TJ, Schinor D, Mrowietz U. Detection of metabolites of fumaric acid esters in human urine: implications for their mode of action. J Invest Dermatol. 2009;129(1): 231-234.

93. Lehmann JC, Listopad JJ, Rentzsch CU, et al. Dimethylfumarate induces immunosuppression via glutathione depletion and subsequent induction of heme oxygenase 1. J Invest Dermatol. 2007;127(4): $835-845$.

94. Ghoreschi K, Brück J, Kellerer C, et al. Fumarates improve psoriasis and multiple sclerosis by inducing type II dendritic cells. J Exp Med. 2011;208(11):2291-2303.

95. Stoof TJ, Flier J, Sampat S, Nieboer C, Tensen CP, Boorsma DM. The antipsoriatic drug dimethylfumarate strongly suppresses chemokine production in human keratinocytes and peripheral blood mononuclear cells. Br J Dermatol. 2001;144(6):1114-1120.

96. Zhu K, Mrowietz U. Inhibition of dendritic cell differentiation by fumaric acid esters. J Invest Dermatol. 2001;116(2):203-208. 
97. Peng H, Guerau-de-Arellano M, Mehta VB, et al. Dimethyl fumarate inhibits dendritic cell maturation via nuclear factor kappaB (NFkappaB) and extracellular signal-regulated kinase 1 and 2 (ERK1/2) and mitogen stress-activated kinase 1 (MSK1) signaling. J Biol Chem. 2012;287(33):28017-28026.

98. Treumer F, Zhu K, Glaser R, Mrowietz U. Dimethylfumarate is a potent inducer of apoptosis in human T cells. J Invest Dermatol. 2003;121(6): 1383-1388.

99. Ockenfels HM, Schultewolter T, Ockenfels G, Funk R, Goos M. The antipsoriatic agent dimethylfumarate immunomodulates T-cell cytokine secretion and inhibits cytokines of the psoriatic cytokine network. Br J Dermatol. 1998;139(3):390-395.

100. Onderdijk AJ, Balak DM, Baerveldt EM, et al. Regulated genes in psoriasis skin during treatment with fumaric acid esters. Br J Dermatol. 2014;171(4):732-741.

101. Wallbrecht K, Drick N, Hund AC, Schon MP. Downregulation of endothelial adhesion molecules by dimethylfumarate, but not monomethylfumarate, and impairment of dynamic lymphocyte-endothelial cell interactions. Exp Dermatol. 2011;20(12):980-985.

102. Rubant SA, Ludwig RJ, Diehl S, et al. Dimethylfumarate reduces leukocyte rolling in vivo through modulation of adhesion molecule expression. J Invest Dermatol. 2008;128(2):326-331.

103. Sebok B, Bonnekoh B, Geisel J, Mahrle G. Antiproliferative and cytotoxic profiles of antipsoriatic fumaric acid derivatives in keratinocyte cultures. Eur J Pharmacol. 1994;270(1):79-87.

104. Bovenschen HJ, Langewouters AM, van de Kerkhof PC. Dimethylfumarate for psoriasis: pronounced effects on lesional T-cell subsets, epidermal proliferation and differentiation, but not on natural killer T cells in immunohistochemical study. Am J Clin Dermatol. 2010;11(5):343-350.

105. Gesser B, Rasmussen MK, Raaby L, et al. Dimethylfumarate inhibits MIF-induced proliferation of keratinocytes by inhibiting MSK1 and RSK1 activation and by inducing nuclear p-c-Jun (S63) and p-p53 (S15) expression. Inflamm Res. 2011;60(7):643-653.

106. Thio HB, Zomerdijk TP, Oudshoorn C, et al. Fumaric acid derivatives evoke a transient increase in intracellular free calcium concentration and inhibit the proliferation of human keratinocytes. Br J Dermatol. 1994;131(6):856-861.

107. Meissner M, Doll M, Hrgovic I, et al. Suppression of VEGFR2 expression in human endothelial cells by dimethylfumarate treatment: evidence for anti-angiogenic action. J Invest Dermatol. 2011;131(6): 1356-1364.

108. BG 12: BG 00012, BG 12/Oral Fumarate, FAG-201, second-generation fumarate derivative - Fumapharm/Biogen Idec. Drugs R D. 2005;6(4): 229-230.

109. Mrowietz U, Reich K, Spellman MC. Treatment of moderate-tosevere psoriasis with oral dimethyl fumarate (BG00012): results of a multicentre, randomized, double-blind, placebo-controlled trial. $\mathrm{BrJ}$ Dermatol. 2006;154:7-8.

110. Wakkee M, Thio HB. Drug evaluation: BG-12, an immunomodulatory dimethylfumarate. Curr Opin Investig Drugs. 2007;8(11): 955-962.

111. Skaria A, Schmid U. Topische behandlung mit fumarsalbe 3\%: eine klinisch-histopathologische studie. Z Hautkr. 1993;68:321-322.

112. de Haan P, von Blomberg-van der Flier BM, de Groot J, Nieboer C, Bruynzeel DP. The risk of sensibilization and contact urticaria upon topical application of fumaric acid derivatives. Dermatology. 1994; 188(2):126-130.

113. Ducker P, Pfeiff B. [Two cases of side effects of a fumaric acid ester - local therapy] Zwei Falle von Nebenwirkungen einer Fumarsaureester - Lokaltherapie. Z Hautkr. 1990;65(8):734-736.

114. Doumit J, Gavigan G, Pratt M. Allergic contact dermatitis from dimethyl fumarate after contact with a Chinese sofa. J Cutan Med Surg. 2012;16(5):353-356.

115. D'Erme AM, Bassi A, Lotti T, Gola M. Dimethyl fumarate contact dermatitis of the foot: an increasingly widespread disease. Int $J$ Dermatol. 2012;51(1):42-45.
116. Schmid UH. Topical application of fumaric acid derivatives. Dermatology. 1995;190(3):253.

117. Skaria AM, Schmid U. Antipsoriatic effect of fumaric acid derivates. J Am Acad Dermatol. 1996;34(2 pt 1):323-324.

118. Van Lumig PP, Driessen RJ, Boezeman JB, Van De Kerkhof PC, De Jong EM. Long-term efficacy of etanercept for psoriasis in daily practice. Br J Dermatol. 2012;166(2):445-447.

119. Racz E, Dolhain RJEM, Thio HB, Prens EP. Psoriasis patients who are less responsive to biologic treatments: switch or combine? Nederlands Tijdschrift voor Dermatologie en Venereologie. 2012;22(2): 117-119.

120. Reich K, Braeu B, Merten K, Griemberg W. Efficacy, safety and dosage of fumaric acid esters in combination with phototherapy in patients with moderate to severe plaque-type psoriasis. J Eur Acad Dermatol Venereol. 2013;27((Reich K.) Dermatologikum Hamburg, Hamburg, Germany):14-15.

121. Wollina U, Langner D. Treatment of disseminated granuloma annulare recalcitrant to topical therapy: a retrospective 10 -year analysis with comparison of photochemotherapy alone versus photochemotherapy plus oral fumaric acid esters. J Eur Acad Dermatol Venereol. 2012;26(10):1319-1321.

122. Gerdes S, Domm S, Mrowietz U. Long-term treatment with fumaric acid esters in an 11-year-old male child with psoriasis. Dermatology. 2011;222(3):198-200.

123. Gunther CH, Schmitt J, Wozel G. Successive use of fumaric acid esters for the treatment of psoriasis vulgaris in a 14-year-old patient. Haut. 2004;15(1):28-30.

124. Stander H, Stadelmann A, Luger T, Traupe H. Efficacy of fumaric acid ester monotherapy in psoriasis pustulosa palmoplantaris. $\mathrm{Br} J$ Dermatol. 2003;149(1):220-222.

125. Pawlak FM, Matthes U, Bacharach-Buhles M, Altmeyer P. Treatment of refractory psoriasis pustulosa generalisata with fumaric acid esters. Aktuelle Derm. 1993;19(1-2):6-8.

126. Peeters AJ, Dijkmans BA, van der Schroeff JG. Fumaric acid therapy for psoriatic arthritis. A randomized, double-blind, placebo-controlled study. Br J Rheumatol. 1992;31(7):502-504.

127. Vlachou C, Berth-Jones J. Nail psoriasis improvement in a patient treated with fumaric acid esters. J Dermatolog Treat. 2007;18(3): 175-177.

128. Mrowietz U, Reich K. Case reports of PML in patients treated for psoriasis. N Engl J Med. 2013;369(11):1080-1081.

129. Fellner A, Dano M, Regev K, Mosek A, Karni A. Multiple sclerosis is associated with psoriasis. A case-control study. J Neurol Sci. 2014;338(1-2):226-228.

130. Gkalpakiotis S, Arenberger P, Gkalpakioti P, Meluzinova E, Chandran D, Arenbergerova M. Management of psoriasis vulgaris and multiple sclerosis with fumaric acid. J Am Acad Dermatol. 2014;70(3): e60-e61.

131. Zecca C, Caporro M, Adami M, Mainetti C, Gobbi C. Fumaric acid esters in psoriasis and multiple sclerosis. Clin Exp Dermatol. 2014;39(4):488-491.

132. Tsianakas A, Herzog S, Landmann A, et al. Successful treatment of discoid lupus erythematosus with fumaric acid esters. J Am Acad Dermatol. 2014;71(1):e15-e17.

133. Winchester D, Duffin KC, Hansen C. Response to ustekinumab in a patient with both severe psoriasis and hypertrophic cutaneous lupus. Lupus. 2012;21(9):1007-1010.

134. Ashrafian H, Czibik G, Bellahcene M, et al. Fumarate is cardioprotective via activation of the Nrf2 antioxidant pathway. Cell Metab. 2012;15(3):361-371.

135. Šilhavý J, Zídek V, Mlejnek P, et al. Fumaric acid esters can block pro-inflammatory actions of human CRP and ameliorate metabolic disturbances in transgenic spontaneously hypertensive rats. PLoS ONE [Electronic Resource]. 2014;9(7):e101906.

136. Gill AJ, Kolson DL. Dimethyl fumarate modulation of immune and antioxidant responses: application to HIV therapy. Crit Rev Immunol. 2013;33(4):307-359. 
137. Cross SA, Cook DR, Chi AW, et al. Dimethyl fumarate, an immune modulator and inducer of the antioxidant response, suppresses HIV replication and macrophage-mediated neurotoxicity: a novel candidate for HIV neuroprotection. J Immunol. 2011;187(10):5015-5025.

138. Schmitt J, Zhang Z, Wozel G, Meurer M, Kirch W. Efficacy and tolerability of biologic and nonbiologic systemic treatments for moderateto-severe psoriasis: meta-analysis of randomized controlled trials. Br J Dermatol. 2008;159(3):513-526.

139. Schmitt J, Rosumeck S, Thomaschewski G, Sporbeck B, Haufe E, Nast A. Efficacy and safety of systemic treatments for moderate-tosevere psoriasis: meta-analysis of randomized controlled trials. $\mathrm{Br} J$ Dermatol. 2014;170(2):274-303.

140. Rapp SR, Feldman SR, Exum ML, Fleischer AB Jr, Reboussin DM. Psoriasis causes as much disability as other major medical diseases. J Am Acad Dermatol. 1999;41(3 pt 1):401-407.
141. Naldi L, Griffiths CE. Traditional therapies in the management of moderate to severe chronic plaque psoriasis: an assessment of the benefits and risks. Br J Dermatol. 2005;152(4):597-615.

142. van de Kerkhof PC. Therapeutic strategies: rotational therapy and combinations. Clin Exp Dermatol. 2001;26(4):356-361.

143. Sizto S, Bansback N, Feldman SR, Willian MK, Anis AH. Economic evaluation of systemic therapies for moderate to severe psoriasis. Br J Dermatol. 2009;160(6):1264-1272.

144. van de Kerkhof P, Barker J, Griffiths CE, International Psoriasis Council, et al. Improving clinical trial design in psoriasis: perspectives from the global dermatology community. J Dermatolog Treat. 2011;22(4):187-193.

145. Barker JN. Methotrexate or fumarates: which is the best oral treatment for psoriasis? Br J Dermatol. 2011;164(4):695.

\section{Publish your work in this journal}

Psoriasis: Targets and Therapy is international, peer-reviewed, open access journal focusing on psoriasis, nail psoriasis, psoriatic arthritis and related conditions, identification of therapeutic targets and the optimal use of integrated treatment interventions to achieve improved outcomes and quality of life. The manuscript management system is completely online and includes a very quick and fair peer-review system. Visit http://www.dovepress.com/testimonials.php to read real quotes from published authors.

Submit your manuscript here: http://www.dovepress.com/psoriasis-targets-and-therapy-journal 